\title{
Developing conceptual understanding of mechanical advantage through the use of Lego robotic technology
}

\author{
Joan M. Chambers, Mike Carbonaro \\ University of Alberta, Canada \\ Hana Murray \\ Elk Island Public Schools, Alberta, Canada
}

\begin{abstract}
Science educators advocate hands on experiences and the use of manipulatives as important for children's conceptual development. Consequently, the utilisation of Lego robotic technologies in teaching and learning has become more prevalent in school science classrooms. It is important to investigate their value as educational tools, particularly their role in helping children develop conceptual understanding of scientific principles. The purpose of this study was to explore the effectiveness of robotic technology with elementary age children, specifically focusing on the children's conceptual development concerning gear function and mechanical advantage. Our results indicate the robot sessions helped develop the students' understanding of gear function in relation to direction of turning, relative speed, and number of revolutions. However, when we examine the children's understanding around the concept of mechanical advantage, we still see the majority of children unable to provide an accurate explanation. The children had difficulty explaining the reasons underpinning their gear arrangement choices for making their robots fast or powerful. The results suggest that providing students with physical experiences is not enough for students to "discover" the relationship of gears to a vehicle's power and speed. A guided inquiry instructional approach is important during the early stages of developing a conceptual understanding of mechanical advantage.
\end{abstract}

\section{Introduction}

Rooted in constructivist theories of learning, science educators advocate hands on experiences and the use of manipulatives as important for children's conceptual development. In concert with this notion, the use of simple robotic building technologies (e.g. LEGO Mindstorms) in teaching and learning has become more prevalent in school science and technology classrooms. It is important to investigate their value as educational tools, particularly their role in helping children develop conceptual understanding of scientific principles. The purpose of this study was to explore the effectiveness of robotic building technology with elementary age children, specifically focusing on the children's conceptual development about gears in a problem solving context. Children in a Year four classroom (8 to 9 years of age) were asked to build a LEGO Mindstorms robot and, through manipulation of the gear configuration, to examine the function of gears with respect to: a) direction of turning, b) relative speed, c) the number of revolutions, and d) mechanical advantages concerning the principles of power and speed. Of particular interest, and the focus for this paper, is the children's conceptual development and understanding concerning 
the last point, mechanical advantage. Unlike direction of turning or speed, understanding of mechanical advantage is difficult for children to develop through direct observation of gear functioning (Lehrer \& Schauble, 1998). We speculated that the use of a robotic vehicle, which behaves in a concrete, observable manner, might address some of the difficulty in observing mechanical advantage at work. Furthermore, through the construction and manipulation of a physical artefact, such as a gear driven robotic vehicle, "students can experience scientific concepts in a variety of different but highly personalized contexts" (Penner, 2001, p. 28). During the study, students engaged in repeated encounters with gears in the context of a functioning robotic vehicle, reflected on what they learned, and received feedback through their engagement with the problem and their peers.

\section{Background to the study}

The development of Lego robotics for classroom use is based on the earlier research work of Seymour Papert (1980). Derived from Piaget's (1964) notion that abstract concepts can be learned through hands on exploratory investigation, Papert created Logo, a programming language designed specifically for children. One of Papert's (1991) major premises is that learners are most likely to generate new ideas when they are actively involved in problem solving that results in external representations (e.g. a Logo program to control the movement of a robotic turtle). The initial work with Logo learning, embedded in a constructivist theoretical framework, formed the groundwork for research partnerships between Lego Corporation and the MIT Media Lab (Martin, Mikhak, Resnick, Silverman \& Berg, 2000), and subsequently with National Instruments and Tufts University (Portsmore, 1999; http://www.ni.com/company/ education/mindstorms.htm; http://www.ceeo.tufts.edu/). As a result of these partnerships, the opportunity for children to design, construct and program robots is finding its way into school classrooms and non-formal educational settings.

Constructivist learning theory contends that learners make their own meaning, thereby generating a unique set of conceptual representations in accordance with their personal experiences (Jonassen, Peck \& Wilson, 1999). Papert (1991) extends the theory of constructivism to encompass the more practical notion of constructionism. According to Papert, the two words differ profoundly. As Kafai and Resnick (1996) state,

One of the main tenets of constructionism is that learners actively construct and reconstruct knowledge out of their experiences in the world ... it places special emphasis on knowledge construction that takes place when learners are engaged in building objects.... [Constructionism] argues that learners are most likely to become intellectually engaged when they are working on personally meaningful activities and projects. In constructionist learning, forming new relationships with knowledge is as important as forming new representations of knowledge. (p.2)

Constructionists approach knowledge formation with an emphasis on physical interactions with objects rather than the abstract formalisations. They believe that working on personally meaningful, context specific projects, which require the manipulation of virtual or concrete objects, will assist students in the learning process (Carbonaro, 1997). Further to this, Penner (2001) suggests "there is a continuous interaction between thought and action. From this perspective, the starting point of all learning resides in the premise that the mind and body are extended and transformed by artifacts situated in activities" (p. 8). 
Robots, being physical objects, fit naturally within this constructionist perspective of learning. Students who engage in the design and construction of robots are actively engaged in their own learning, developing problem solving skills, utilising higher order thinking skills, and often working in collaboration (Chambers \& Carbonaro, 2003). Robotics, as an educational tool, enables students to learn in an active, constructionist environment, building physical objects and experiencing abstract concepts in intentionally meaningful ways. Research on the use of robotics in classrooms indicates their use promotes problem solving abilities and augments children's understanding of scientific, mathematical, and design concepts (Druin \& Hendler, 2000; Gallagher \& Bauerle, 2003; Wagner, 1998).

Research around the design and building of sharable artefacts suggests model or robot building, in a constructionist learning context, is an important educational activity (Penner, 2001). Several researchers have used the gear domain as a starting point and context for learning. For example, Metz (1991) explored how elementary children think about gears through the use of physical models. Children constructed a variety of gear arrangements on a gearboard and used a "think out loud" strategy to explain what they were doing and thinking. The main focus of Metz's research is on the development of preschool and elementary children's explanations of movement and jamming of gears. Shook's (2000) research also centred on gear function and motion; her research explores scaffolding and suggests that "learning to question how and why things move can lead to a more complete synthesis of the core ideas behind motion and mechanism, the by-product being enhanced spatial reasoning skills" (p. 15). Other research focused on identifying classroom practices that support children in developing theoretical mathematical thinking utilising concrete, everyday referents (i.e. gears) (Bartolini Bussi, Boni, Ferri \& Garuti, 1999). Dixon and Bangert (2002) focused their investigation on how developmental changes may influence representational change during knowledge acquisition about gears. And Lehrer and Schauble (1998) explored how Years two and five children reason with gears using a gearboard, an eggbeater, and a bicycle. Their study suggests,

\begin{abstract}
Many of the conceptions that children apply to understanding gears are reasonable rules about the way the world usually works, but do not apply in the context of gear trains.... [Consequently] the instructional challenge is to identify a means to encourage children to go beyond merely noticing empirical regularities or patterns, to search for explanations that would account for those observed regularities. (p. 23-24)
\end{abstract}

Building on prior research utilising gear models, our purpose is to explore children's understanding of gear functioning through the use of Lego robotic technology. We examine robotic, gear driven vehicles as a means for concretising the principles of mechanical advantage in an engaging, personally meaningful way for young children.

\title{
Method
}

This study modifies and extends the work of Lehrer and Schauble (1998) by allowing children's understanding of gears to develop through their hands on experience of robot construction and gear configuration manipulation. As Shook (2000) suggests, "exposing children to mechanisms through construction activities, [help] children gain a practical understanding of how certain mechanisms create distinct motions" (p. 17). The research process centred on an instructional intervention utilising Lego robotic, gear driven vehicles as an educational tool, and included pre and post-intervention interview questions concerning the children's understanding of gear motion and 
function. We made modifications to the original interview questions concerning gear combinations used by Lehrer and Schauble. The data collection and experimental intervention process were also modified. For example, we used verbal interview pre and post-test questions rather than a printed format and, based on the previous findings from Lehrer and Schauble's work, limited the number of gear combinations. Students were asked to predict what would happen for each set of gear combinations as well as manipulate the gears to confirm or reject their predictions. In order to more clearly measure gains in understanding, the pre and post-test items were identical. Additionally, the students were asked to reason about gears in the context of modifying simple robot vehicles, thus giving them the opportunity to concretely explore the mechanical advantage of gears.

The study involved a Year four class of 22 students (10 girls and 12 boys) from a rural school setting. Year four students (9 to 10 years of age) were purposely chosen; the concepts dealing with gears are directly connected to the curriculum and taught at the Year four level as part of the science units on Wheels and levers and Building devices and vehicles that move (Alberta Learning, 1996). These units involve understanding concepts related to simple machines and designing and constructing a vehicle, and engage students in the processes of scientific inquiry and problem solving through technology. Because learning about gears is only one of the fundamental components in these science units, it allowed the researchers to conduct this study independently of what the students explored in their regular science classes with their homeroom teacher.

All students participated in the study but one of the data sets had to be withdrawn due to incompleteness of the data. The students were organised into six collaborative groups based on recommendations from the Year four homeroom teacher. The students participated in six afternoon sessions using LEGO robotic materials over a sixweek period (three sessions of about 120 minutes, one session of about 90 minutes, one session of about 20 minutes, and a final session of about 150 minutes) as well as pre and post-test sessions. The robotics sessions were held in the Year four homeroom classroom. Materials for the pre and post-test included the LEGO Dacta Early Simple Machines II Student Set \#9654, and the Team Challenge Set \#9794 (see LEGO Product search at http://www1.lego.com/education/search/). The robot sessions required eight Team Challenge Sets to accommodate the number of students in the class. Other materials required for the student inquiry were a set of rechargeable batteries, stopwatches, washers, and plastic containers.

The study is divided into three phases: a) pre-test on gear understanding; b) intervention, student robot building and gear reconfiguration and testing; and c) posttest on gear understanding. Prior to the pre-test, students received a general overview of $L E G O$ robotics without any explanation of gears. The purpose of this session was for the students to become familiar with the operation of the Mindstorms kits and to stimulate motivation for the forthcoming activity.

\section{Pre-test}

After the brief introduction to $L E G O$ robotics, the students were administered a 20 to 25 minute, two-part pre-test to ascertain their knowledge of and reasoning about gears. Students were interviewed individually with the questions read aloud to them. The researchers wrote the answers down, so that students were not constrained by having to respond in writing. The students received no formal teaching about gears in their science unit prior to the pre-test. 
The first part of the pre-test included student predictions about gear motion and function before the students were given the opportunity to manipulate the gears. The focus was on how the driver gear (leftmost gear) affects the follower gear (rightmost gear) with respect to: a) the direction of follower gear; b) the follower gear's speed; and c) the number of revolutions the follower gear completes as a result of turning the driver gear one revolution. Figure 1 shows the gear configurations used in the pre-test. For example, with respect to gear teeth configuration ratio 24: 8: 24, students were asked to answer a series of predetermined questions: a) What will happen if I spin the first red gear in this direction? Why? b) Spin the first red gear. What happens to the direction of the second red gear? Why? c) Does the second red gear go faster, slower, or the same speed as the first red gear? Why? d) If the first red gear goes around one time, how many times will the second red gear go around?
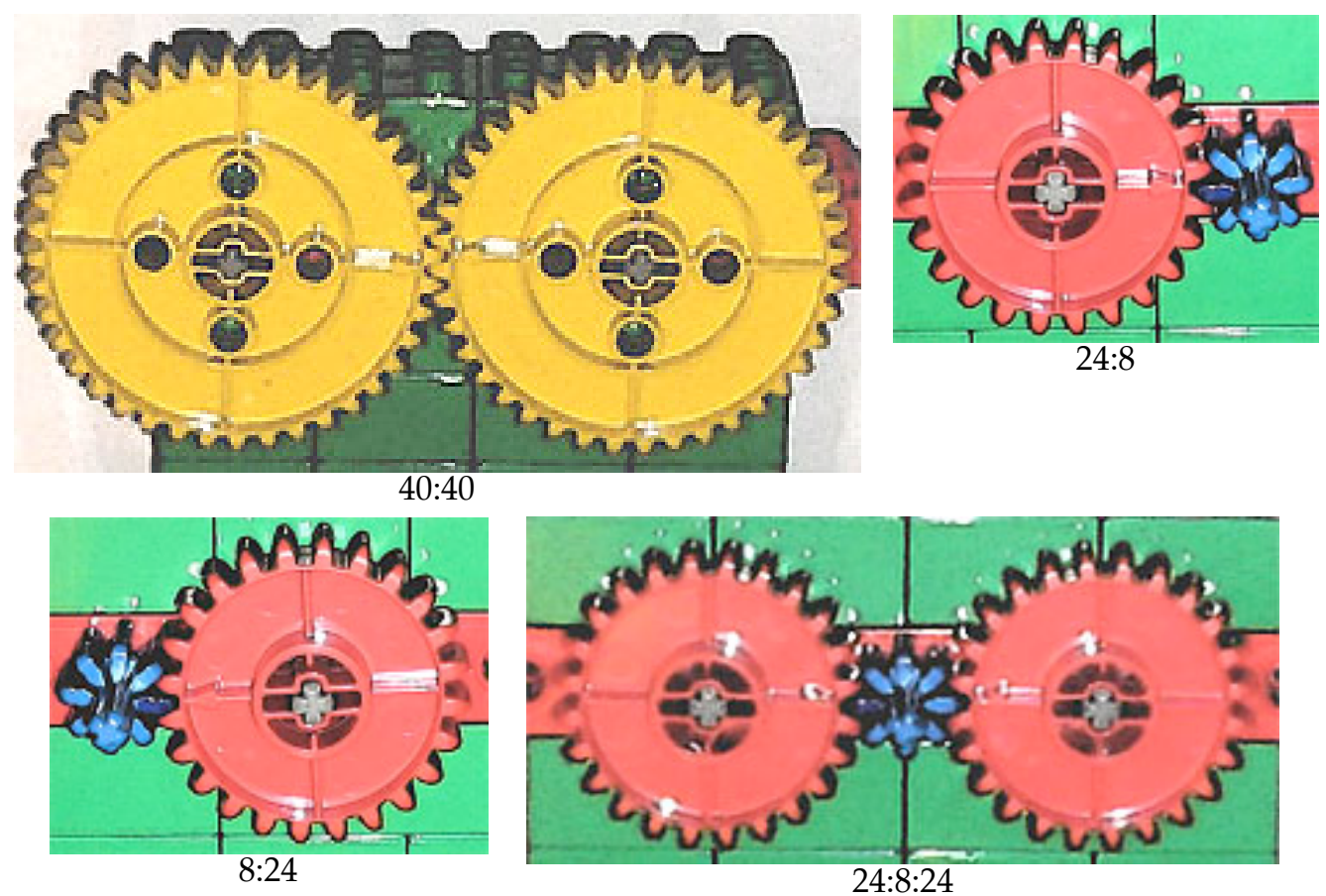

Figure 1: Gear configurations labelled according to gear teeth ratios

In the second part of the pre-test, the students were asked to observe and inspect two moving robots that had different gear ratios and to infer why the robots behaved differently. Built according to the modified TankBot instructions (Robotics Academy, 2002), the two robots were identical except for the switched gear arrangement and the colour (see Figures 2 and 3). The colour was used to distinguish between the two robots. The yellow robot had a 40-tooth gear on the motor and a 16-tooth gear on the wheel axle. The green robot had a 16-tooth gear on the motor and a 40-tooth gear on the wheel axle (see Figure 3). The robots were both programmed to move straight ahead until it hit a container of 40 washers (weights) that were $35 \mathrm{~cm}$ away from the robot. The students answered several questions about each robot based on their observations of the robot movement and physical examination of the robots (the students were not told what to watch for nor about the different gear arrangements): a) 
What did you observe (see) when I turned on the yellow robot? b) What did you observe (see) when I turned on the green robot? c) What is the difference in the behaviour between the yellow and the green robots? d) Why do the two robots behave differently? We were interested in what inferences the students made based upon their observations. Were they able to make connections between the first part of the pre-test on gears to the second part of the pre-test where the gears were part of a machine?

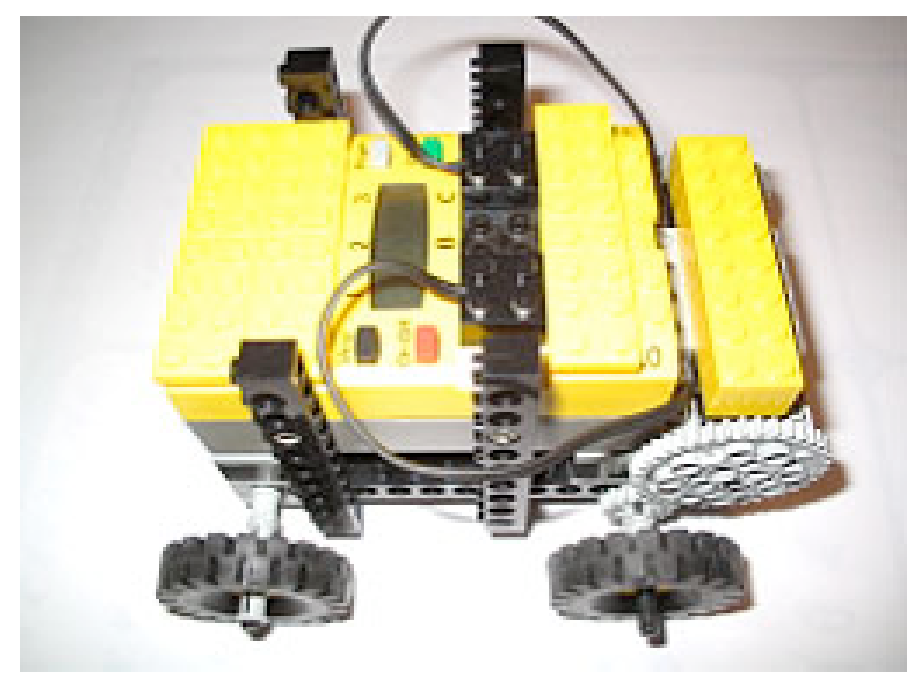

Yellow robot: 16-tooth gear on wheel axle, 40-tooth gear on motor

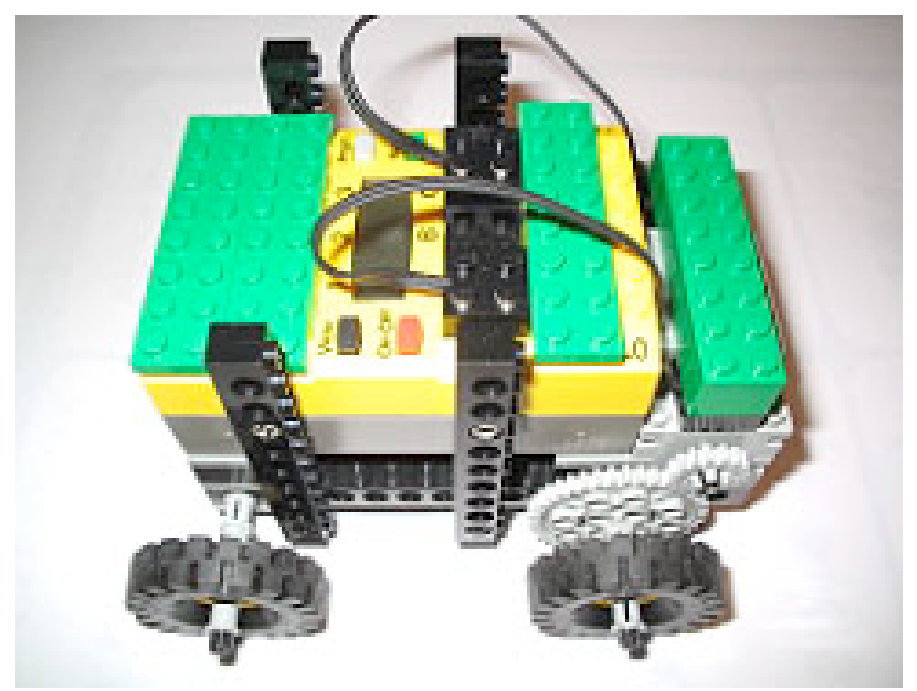

Green Robot: 40-tooth gear on wheel axle, 16-tooth gear on motor

Figure 2: Two different coloured robots configured with different gear ratios.

\section{Intervention}

The intervention consisted of a semi-structured, guided scientific inquiry approach. The researchers wanted the students to think about and explore different gear ratio 


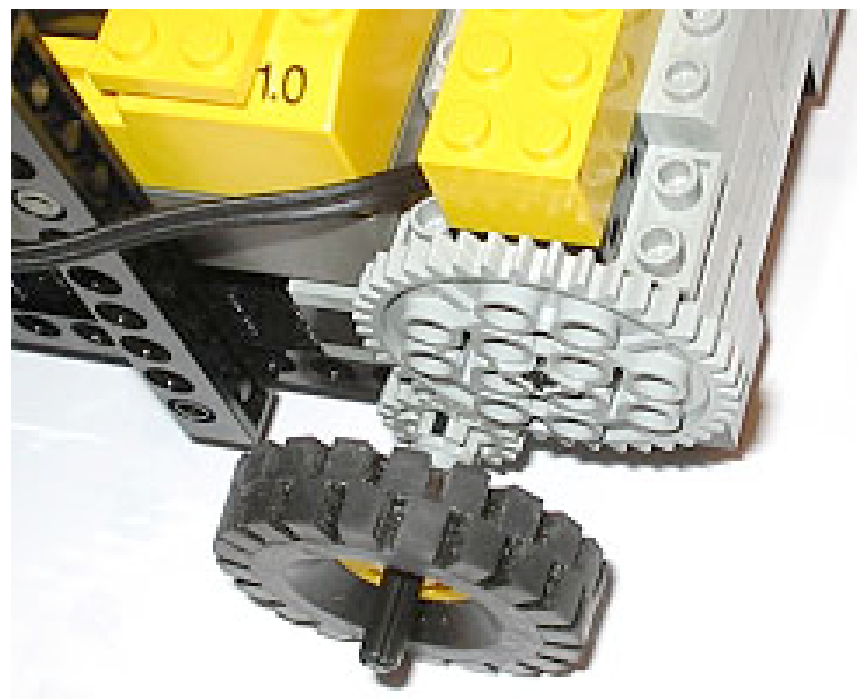

Yellow robot

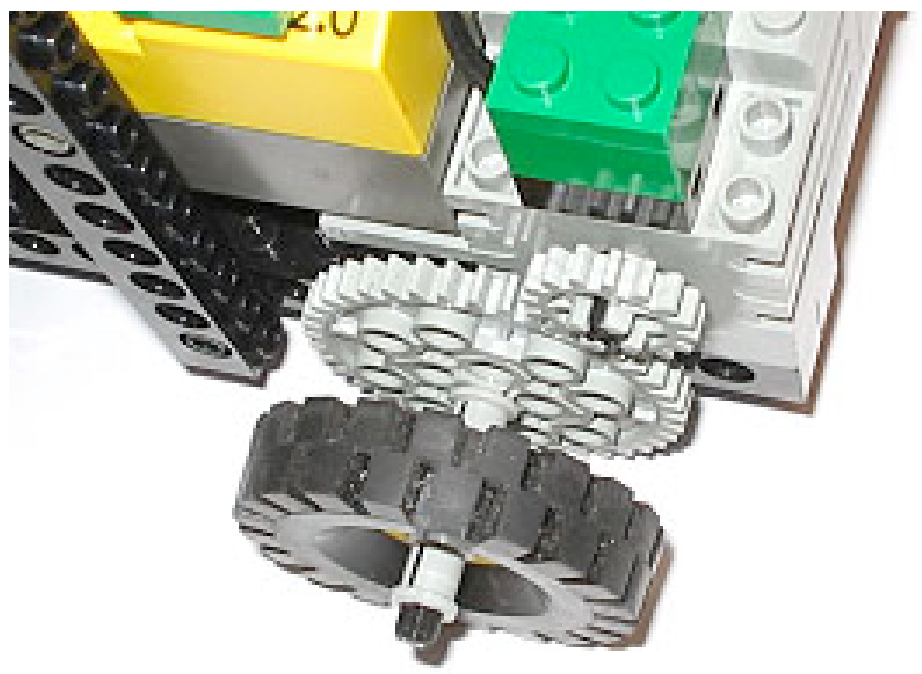

\section{Green robot}

Figure 3: Close-up of gear arrangements on robots.

combinations in order to develop their understanding of the affect gears have on speed and power. The students were asked, using a modified TankBot design, to substitute different gear combinations in order to explore the mechanical advantage of gears. They were limited to the following spur gear sizes: 40, 24, 16, and 8 (gear teeth). Over three sessions (total time of five and a half hours) students were asked to complete the following tasks for each gear ratio combination they chose to use:

a. to draw the gear combination and label the gear on the motor and the wheel axle with the number of teeth; 
b. to time the robot over a three metre distance;

c. to count the number of weights (washers) the robot could push (see Figure 4); and

d. to record any observations and reflections about their robots.

A logbook (template) was created for the students so they could record the relevant data easily, including diagrams, labels, observations, and reflections. As Schauble (1990) pointed out, young children's record keeping is very limited; therefore, a template with categories for recording observations would help make data entry easier and more complete.

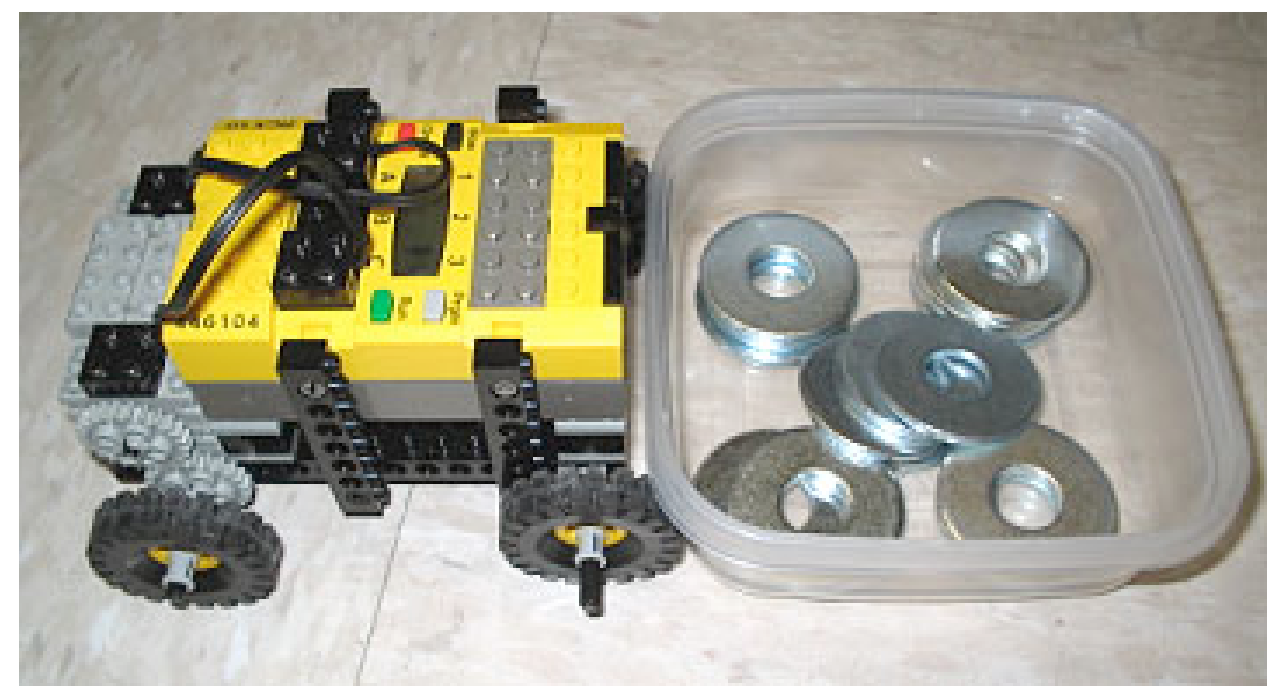

Figure 4: Student built robot pushing a container of weights (washers)

\section{Post-test}

After the three building sessions with gears, the students were given a post-test, identical to the pre-test, but without the prediction questions. The post-test was given in a similar manner to the pre-test, with the researchers reading the questions and recording student responses; the post-testing took an average of 15-20 minutes per student.

\section{Results}

The focus of this paper is on the student's notions regarding mechanical advantage, that is power and speed. Accordingly, the results section centres on the data obtained from student interaction with the robots. Pre and post-test interview data regarding the robots as well as data from student logbooks recorded during the intervention phase of the research forms the basis for this results section and the discussion that follows.

\section{Student robot observations and inferences}

An examination of student answers to the interview questions about the robots shows that most children described correctly what they saw happening on both the pre-test 
and the post-test. When asked on the pre-test what the students observed when the yellow robot was turned on, they generally answered that the robot moved forward in a straight line, stopping when it hit the container with the washers. Because the students did not have a point of reference on the first robotic question, they did not, with the exception of one student, say that the robot moved fast. However, as the children moved to the next question about the green robot they began using some comparisons such as, the robot moved forward slower and pushed the weights. On the post-test, the students indicated that the yellow robot was faster and weaker than the green robot and that the green robot was slower but more powerful than the yellow robot. For the purpose of this study, colloquial terms such as faster/slower and weaker/powerful/stronger were used, since many of the children initiated the use of these terms and were familiar with their meanings.

On both the pre and post-tests, the majority of the students identified gears as the reason for the different robot behaviour (see Figure 5). However, in addition to the gear answers, many of the student answers also included additional guesses. For example on the pre-test, some students thought the RCXs (LEGO Computer Brick) may be programmed differently (the brief exposure prior to the pre-test cued students to the fact that the RCXs can be programmed), or that the yellow robot may have a faster engine than the other one, or that the big gear is almost touching the ground on the green robot and therefore helps to push (making it more powerful), or that motors may be different, or the little gear on top is controlling it [the speed], and so on. Those students who did not mention gears as the reason for the different behaviour, either did not know the reason or said that the green robot had a stronger battery or because the two robots did not like each other.

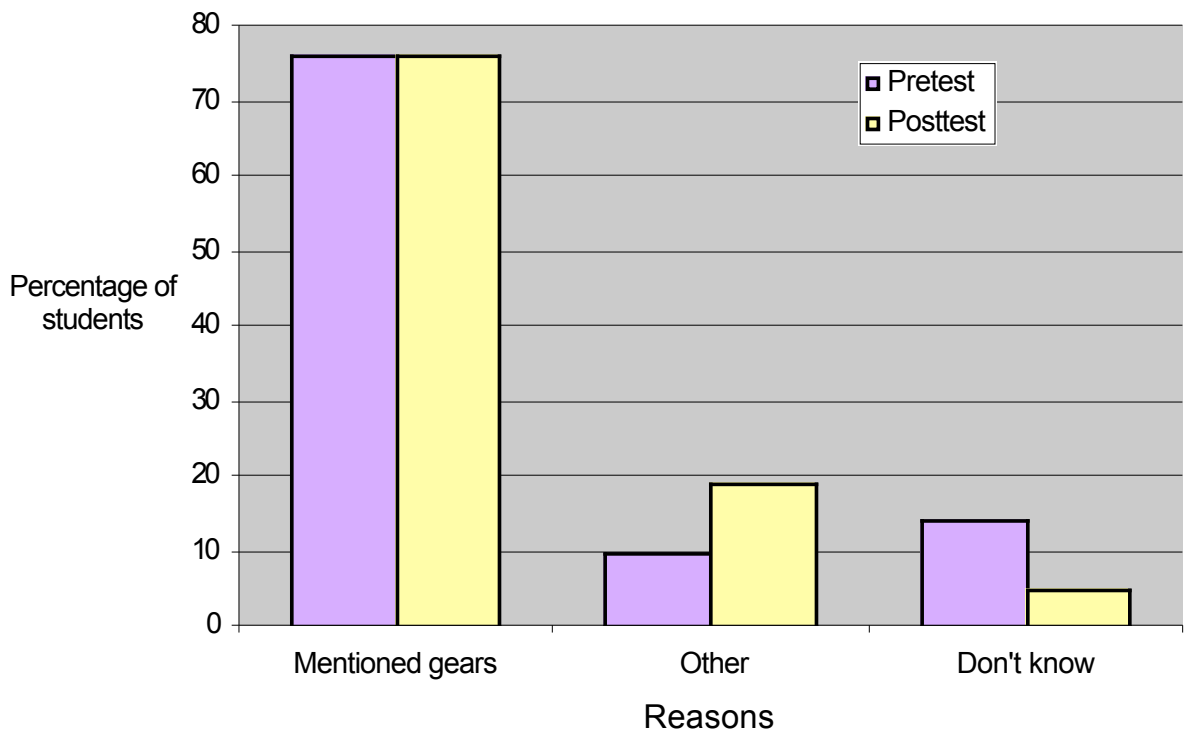

Figure 5: Percentage of students indicating the reasons for the different robot behaviour $(n=21)$.

Conversely, on the post-test, those students who mentioned gears as a reason for speed or power focused mostly that gears are switched around and did not offer any other explanations. They offered a clearer description of where the gears are, instead of just 
saying the gears are switched or different. On the post-test there was only one student who did not offer an explanation, but several other students additionally indicated that the robots were different, or one of the robots had a "metal thing" [AC adapter port], or because one pushes more or that the axles are switched around. More students identified gear placement switch on the post-test than on the pre-test. Also there was a small increase in the number of students who identified revolutions of the gears as a reason why the two robots behave differently. For example, one student answered, "Because of the gears. [They are] switched around. If big wheel goes around once, small will go around more times because of how [they are] put together."

\section{Fast and powerful robots - information from student logbooks}

This results section centres on the student logbooks. Students used their experimental data to explain which gear combination would make their robot either fast or powerful. After analysing the student responses, five common categories emerged; their explanations focused on big gears, placement of gears, revolutions, other, and simply not knowing or no responses given (see Figure 6).

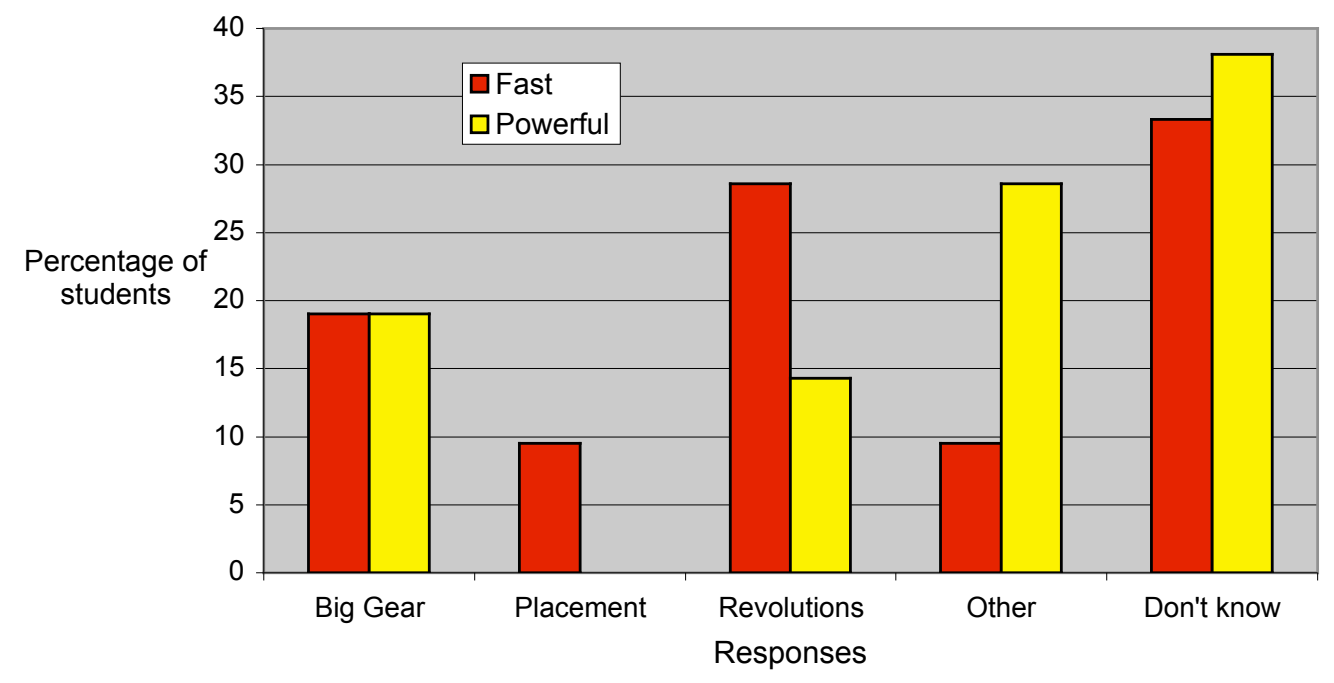

Figure 6: Percentage of Year 4 students indicating "Why do the chosen gear combinations make your robots go fast or be more powerful?"

Fast robots: The majority of students were not able to explain why the chosen gear combination made their robot faster. However, the remaining students had some explanation as to why their gear combinations made their robot faster, for example, the number of revolutions. These students stated that the little gear on the wheel axle had to revolve faster than the big gear on the motor, thus making it move much faster. Other students used the explanation of the big gear doing the pushing and thus making the robot go faster. A small number of students used gear placement as their reasoning for faster robots. They simply stated where the gears were without mentioning anything else.

Powerful robots: Explaining why the robots are more powerful was difficult for the students. The majority of students were not able to explain why the chosen gear 
combination made their robot more powerful, and another large group of students had other unrelated and unclear answers. Some students used the big gear explanation as to why their robots were powerful. They explained that the big gear was doing the pushing and as well, those students who used two large gears (40:40), indicated that two big gears equals more power. Some of the students used an explanation of revolutions as their reason. They stated that the big wheel on the wheel axle is slower; therefore, it is more powerful. None of the students used the placement of gears in their explanations.

In summary, all students chose a large gear on the motor and a smaller gear on the wheel axle gear arrangement for the fast robots. However, there was not as much agreement among the students about the gear combination of powerful robots. Still, the majority of students chose the correct answer that the small gear should be on the motor and the large gear on the wheel axle. Another group chose same-to-same ratio to create a more powerful robot. For example, one student chose a 24:24 ratio, while the rest (seven students) chose a 40:40 ratio, believing that larger gears have more power. As could be seen from the results, the concept of mechanical advantage was difficult for students to grasp.

\section{Discussion}

This study explored how elementary children in Year four reason about gear function, specifically, their understanding of mechanical advantage. It confirms previous findings that there is variability among children in how they reason about gears (Lehrer \& Schauble, 1998) as well as differences in conceptual development and understanding within each individual student (Fischer \& Immordino-Yang, 2002). According to Granott (2002), variability is an important part of developmental learning and a necessary developmental attribute in order for change to occur. Accordingly, this study highlights the importance of appropriate and timely intervention on the part of the teacher in order to address variability in learning and support children as they develop understanding of difficult concepts, such as mechanical advantage.

Overall, the robot building sessions seemed to improve the students' post-test scores on the majority of the questions concerning direction of turning, relative speed, and the number of revolutions. However, when we examine the children's developing understanding around the concept of mechanical advantage, we still see the majority of children unable to provide an accurate explanation. The children had difficulty explaining the reasons underpinning their gear arrangement choices for making their robots fast or, especially, powerful. In some cases the children seemed to hang on to their prior beliefs. According to Schauble (1990), "people tend to interpret identical patterns of evidence differently, depending on whether that evidence confirms or disconfirms their prior beliefs" (p. 54). For example, one of the most strongly held beliefs of many of the students was the idea that two large gears will be the strongest. This is not unusual, since the children are probably drawing from their own life experiences that bigger or larger objects or machines are more powerful.

Another misconception the students held, when asked which robot would be faster, was the belief that the big gear is doing the pushing, and therefore the robot will go faster. Again, this likely comes from prior beliefs that bigger equals faster and stronger. It is this strongly held prior belief, based on personal experience of phenomena and informal knowledge, which potentially influenced the children's understanding and 
scientific concept development concerning gear configuration and mechanical advantage (Driver, Asoko, Leach, Mortimer \& Scott, 1994; Chang et al., 2007).

The children's prior conceptions of how gears function appeared, for many of the students, to conflict with accepted scientific knowledge of mechanical advantage (Penner, 2001); a conflict that was not overcome even though the children were given several opportunities to experience gear function with the robots. Our thinking behind the use of the Lego robotic vehicles was that it would enable the children to concretely "see" speed and power in action, so to speak, as the robot physically pushed more weight or moved faster depending on gear arrangement. Penner (2001) suggests, "[scientific models] support the production of a simpler version of a phenomenon in order to focus one's investigation on particular features of the phenomenon. Central to the development of a physical model is the specification of how model components are related" (p. 10). What our results suggest is that the children needed further experience with gear components before they could apply this developing understanding of gear function as part of a relatively complex system (i.e. robotic vehicle). For example, the children could explore gear action using simple gear boards prior to encountering gears on robotic vehicles. Additional inquiry into gear function through the exploration of gears on simple machines, such as an eggbeater, would promote children's knowledge of gear function.

Framed within constructivist/constructionist thinking, Lui (2000) suggests children's "reasoning develops as their physical experience increases" (p. 18). However, our results suggest that providing students with physical experiences and a framed set of questions is not enough for students to "discover" the relationship of gears to a vehicle's speed and, especially, power. Recently, there have been a number of strong arguments made as to why minimal guidance during instruction is often less effective and less efficient than a structured and/or guided instructional approach (Mayer, 2004). According to Kirschner, Sweller and Clark (2006) "not only is unguided instruction normally less effective; there is also strong evidence that it may have negative results when students acquire misconceptions or incomplete or disorganized knowledge" (p. 84). They further suggest that situations where children engage in scientific inquiry without feedback from the teacher, relying only on the feedback received from their direct engagement with the problem or the interaction with their peer group may not suffice for adequate learning. Furthermore, Perry and Elder (1997) suggest that repeated encounters with a problem do not necessarily lead to improved understanding. In their research, they "only observed [that] improvement came immediately after instruction" (p. 154).

It would seem plausible that instruction given at critical points of students' learning with the LEGO robots would be necessary. In this way, the students' learning can be scaffolded in the Vygotskian sense, whereby carefully chosen activities and experiences are modelled and supported through collaborative student-teacher and/or expert-novice interactions (Wyeth, Venz \& Wyeth, 2004). The critical points identified as part of our study would include the times when students completed individual robot building sessions, which incorporated switching of the meshed gears, the timed trial, and the strength test. For example, class results could be collected and displayed on a large chart, and the teacher could then initiate discussion about the children's results and reflections. Or the children could be allotted time to examine the differences in robot construction and consequent behaviour among the student groups. As Howe (1996) states, "children need time to move back and forth between everyday concepts and scientific concepts" (p. 48). And as Penner (2001) suggests, it is important 
"for students to construct and share artifacts. Learning is not just the communication of facts from a teacher to a student; it is also the process of developing collective sense making" (p. 19-20).

Lego robots, as sharable artefacts, can facilitate inquiry based, collaborative, and carefully scaffolded learning. But how can teachers best make use of this emerging technology? What links do children construct between the gear action of the robotic vehicles and their prior understanding of gear function? Research that explores children's thinking as they move from everyday understanding of gears and mechanical advantage to a scientific understanding of these concepts would be useful, such as a longitudinal study to investigate at what point in their cognitive development children begin to more fully and concretely understand mechanical advantage. Is there an optimum age to introduce this difficult scientific concept to children? Additionally, research is needed which explores the potential of robotic technology as a tool for enhancing student learning of scientific concepts. As this technology increasingly penetrates into our classroom environments at a younger age level, research is also necessary into appropriate pedagogies for scaffolding student learning.

In conclusion, results from this study support current understanding; that being, children will have various reasons for their answers and will be at various levels of development (Fischer \& Immordino-Yang, 2002). Therefore, teachers need to be prepared to accommodate for variability. Additionally, this study points to the need for thoughtful construction of lesson activities on the part of the teacher, uncovering common student preconceptions and guiding the children through scientific inquiry. Carefully planned and scaffolded instruction and discussion at critical points of their inquiry will better help young children develop their scientific knowledge and understanding. Lego robotics has the potential to be an effective tool to support and enhance learning as children develop understanding of difficult scientific concepts like mechanical advantage.

\section{References}

Alberta Learning (1996). Science. Edmonton, AB: Alberta Learning. [viewed 12 Oct 2006] http:/ / www.learning.gov.ab.ca/k_12/curriculum/bySubject/science/elemsci.pdf

Bartolini Bussi, M. G., Boni, M., Ferri F. \& Garuti R. (1999). Early approach to theoretical thinking: Gears in primary school. Educational Studies in Mathematics, 39, 67-87.

Carbonaro, M. (1997). Making technology an integral part of teaching: The development of a constructionist multimedia course for teacher education. Journal of Technology and Teacher Education, 5(4), 255-280.

Chambers, J. \& Carbonaro, M. (2003). Designing, developing and implementing a course on LEGO robotics for technology teacher education. Journal of Technology and Teacher Education, 11(2), 209-241.

Chang, H-P., Chen, J-Y., Guo, C-J., Chen, C-C., Chang, C-Y., Linf, S-H., et al. (2007). Investigating primary and secondary students' learning of physics concepts in Taiwan. International Journal of Science Education, 29(4), 465-482.

Dixon, J. A. \& Bangert, A.S. (2002). The prehistory of discovery: Precursors of representational change in solving gear system problems. Developmental Psychology, 38, 918-933. 
Driver, R., Asoko, H., Leach, J., Mortimer, E. \& Scott, P. (1994). Constructing scientific knowledge in the classroom. Educational Researcher, 23(7), 5-12.

Druin, A. \& Hendler, J. (2000). Robots for kids: Exploring new technologies for learning. San Diego, CA: Academic Press.

Fischer, K. W. \& Immordino-Yang, M. H. (2002). Cognitive development and education: From dynamic general structure to specific learning and teaching. [viewed 12 Oct, verified 30 Jun 2008] http: / / www.gse.harvard.edu/ ddl/articlesCopy/SpencerPaperFinalFigs0302.pdf

Gallagher, M. \& Bauerle, A. (2003). Toying with technology: Bridging the gap between education and engineering. Proceedings of the Society for Information Technology and Teacher Education International Conference, 2003 (1), 3538-3541.

Granott, N. (2002). How microdevelopment creates macrodevelopment: Reiterated sequences, backward transitions, and the Zone of Current Development. In N. Granott \& J. Parziale (Eds.), Microdevelopment: Transition process in development and learning. (pp. 213-242). Cambridge, UK: Cambridge University Press.

Howe, A. C. (1996). Development of science concepts within a Vygotskian framework. Science Education, 80(1), 35-51.

Jonassen, D. H., Peck, K. L. \& Wilson, B. G. (1999). Learning with technology: A constructivist perspective. Upper Saddle River, NJ: Prentice-Hall Inc.

Kafai, Y. \& Resnick, M. (1996). Introduction. In Y. Kafai \& M. Resnick (Eds.), Constructionism in practice: Designing, thinking and learning in a digital world (pp. 1-8). Mahwah, NJ: Erlbaum.

The LEGO Group (2000). Introductory activities for Lego Dacta Set \#9790. Billund, Denmark: The LEGO Group. http:/ / www.lego.com/

Lehrer, R. \& Schauble, L. (1998). Reasoning about structure and function: Children's conceptions of gears. Journal of Research in Science and Technology, 35(1), 3-25.

Lui, X. (2000). Elementary school students' logical reasoning on rolling. International Journal of Technology and Design in Education, 10, 3-20.

Martin, F. G., Mikhak, B., Resnick, M., Silverman, B. \& Berg, R. (2000). To Mindstorms and beyond: Evolution of a construction kit for magical machines. In A. Druin \& J. Hendler (Eds.), Robots for kids: Exploring new technologies for learning (pp. 10-33). San Diego, CA: Academic Press.

Metz, K. E. (1991). Development of explanations: Incremental and fundamental change in children's physics knowledge. Journal of Research in Science Teaching, 28(9), 785-797.

Papert, S. (1980). Mindstorms: Children, computers and powerful ideas. New York: Basic Books.

Papert, S. (1991). Situating constructionism. In I. Harel \& S. Papert (Eds.), Constructionism (pp.111). Norwood, NJ: Ablex Publishing Corporation.

Penner, D. E. (2001). Cognition, computers, and synthetic science: Building knowledge and meaning through modeling. In W. G. Secada, (Ed.), Review of Research in Education. (pp. 1-35). Washington, DC: American Educational Research Association.

Perry, M. \& Elder, A. D. (1997). Knowledge in transition: Adult's developing understanding of a principle of physical causality. Cognitive Development, 12, 131-157.

Piaget, J. (1964). Cognitive development in children: Development and learning. Journal of Research in Science Teaching, 2, 347-358.

Portsmore, M. (1999). RoboLab: Intuitive robotic programming software to support lifelong learning. Learning Technology Review, Spring/Summer, 26-39. 
Robotics Academy (2002). TankBot building instructions. [viewed 12 Oct 2006, verified 30 June 2008] http:/ / www.education.rec.ri.cmu.edu/roboticscurriculum/teachertraining/tankbotbldginstr.pdf

Schauble, L. (1990). Belief revision in children: The role of prior knowledge and strategies for generating evidence. Journal of Experimental Child Psychology, 49, 31-57.

Shook, M. L. (2000). Scaffolding children's exploration of motion and mechanism. Unpublished MS thesis, Massachusetts Institute of Technology. [verified 15 Aug 2008] http:/ / dspace.mit.edu/ bitstream/handle/1721.1/28247/50683969.pdf?sequence=1

Wagner, S. P. (1998). Robotics and children: Science achievement and problem solving. Journal of Computing in Childhood Education, 9(2), 149-192.

Wyeth, P., Venz, M. \& Wyeth, G. (2004). Scaffolding children's robot building and programming activities. In RoboCup 2003: Robot Soccer World Cup VII (pp. 308-319). Berlin: Springer.

Joan M. Chambers, Postdoctoral Fellow, Department of Secondary Education, University of Alberta, 341 Education South, Edmonton, AB, Canada T6G 2G5.

Email: joan.chambers@ualberta.ca

Mike Carbonaro, Associate Professor, Department of Educational Psychology

University of Alberta, 6-102 Education North, Edmonton, AB, Canada T6G 2G5.

Email: mike.carbonaro@ualberta.ca

Hana Murray, M. Ed., Teacher, Elk Island Public Schools, 683 Wye Road, Sherwood

Park, Alberta, Canada T8B 1N2. Email: hana.murray@interbaun.com 